\title{
Effect of Separated Over-Fire Air angle on the Temperature Deviation of Final Super-Heater in a 500 MW Tangentially Coal-Fired Boiler
}

\author{
Kang Min Kim, Seok Gi Ahn, Chung Hwan Jeon \\ School of Mechanical Engineering, Pusan National University \\ Jangjeon 2-dong, Geumjeong-gu, Busan 609-735, Republic of Korea \\ wjddus0969@naver.com; seokgi0502@naver.com; chjeon@pusan.ac.kr
}

\section{Extended Abstract}

In this paper, the CFD simulation in the $500 \mathrm{MW}$ tangentially fired pulverized-coal boiler is performed to investigate and reduce the gas temperature deviation in front of the final super-heater. The 3-D mesh is composed of 1,126,947 hexahedron cells and the calculations were supported by FLUENT 16.1. In the prior research, the clockwise residual airflow swirling in upper furnace caused higher velocity at the left side of crossover pass. The yaw and tilt angles of SOFA(separated over-fire air) in the domestic two-pass boiler in commercial operation are different with a design conditions to decrease unburned-carbon caused by using sub-bituminous coals. Therefore, on the basis of the present angles of SOFA in commercial boiler, the yaw angles were adjusted in order to reduce residual swirling and the influence of tilt angles was also investigated against increasing of unburned-carbon. In the results, the temperature distributions of final super-heater did not always conform to velocity distribution as some of coal particles combusted in the crossover pass. In some case, the severe temperature deviation still remained though super-heater velocity distribution is comparatively closer to the ideal distribution. Therefore, both of the residual swirling and combustion in the crossover pass were important factor for the deviation.

\section{References}

[1] C. Yin, S. Caillat, J. L. Harion, B. Baudoin, and E. Perez, "Investigation of the flow, combustion, heat-transfer and emissions from a 609 MW utility tangentially fired pulverized-coal boiler," Fuel, vol. 81, no. 8, pp. 997-1006, 2002.

[2] D. Tian, L. Zhong, P. Tan, L. Ma, Q. Fang, and C. Zhang, "Influence of vertical burner tilt angle on the gas temperature deviation in a 700 MW low NOx tangentially fired pulverised-coal boiler," Fuel Processing Technology, vol. 138, pp. 616-628, 2015.

[3] H. Y. Park, S. H. Baek, H. H. Kim, Y. J. Kim, T. H. Kim, H. S. Lim, and D. S. Kang, "Reduction of main steam temperature deviation in a tangentially coal-fired, two pass boiler," Fuel, vol. 166, pp. 509-516, 2016. 